\title{
Collaborative Pedagogy in a Design Thinking Education Course
}

\author{
Rosetta Marantz Cohen, EdD \\ Myra M. Sampson Professor of Education and Child Study \\ Smith College \\ Lucy Mule, $\mathrm{PhD}$ \\ Associate Professor, Department of Education and Child Study \\ Smith College
}

\begin{abstract}
This article describes a co-taught course that mobilized a Design Thinking approach in the service of creating a prototype for an actual girls' boarding school in Kenya. The goal of the class was to allow students to engage collaboratively with faculty, with their peers, and with experts "on the ground" to develop the various parts of the school, from the mission to the curriculum to the building design. The article describes the rewards and complexities of this kind of hands-on pedagogy in a higher education context.
\end{abstract}

"Learning occurs when teachers exercise control indirectly through work done as a social enterprise in which all individuals have an opportunity to contribute to something about which all feel a responsibility" (Dewey, 1997).

At Smith College in Northampton, MA, as in many other colleges and universities around the United States, "collaboration" has become a popular and commonplace term. In evaluating faculty for tenure, we have come to value and reward collaborative work within and across the disciplines. In designing our courses, we see student collaboration as a critical "soft skill," crucial to the learning process. We value co-teaching as a useful (if expensive) tool for modeling critical discourse, and we encourage both faculty and students to collaborate in their research with scholars around the world. Indeed, global collaboration has emerged as one of the most robust and burgeoning forms of intellectual sharing, as technology facilitates communication in ways that would have been impossibly cumbersome even a decade ago.

Collaboration, however, is often complicated: student group work is hard to monitor and evaluate, co-teaching is time-consuming, and personalities get in the way of easy interactions. Time differences and technological difficulties complicate online global collaborations. And yet, the collaborative sharing of knowledge and expertise can be rewarding in unprecedented ways, as the walls defining knowledge grow porous, and the possibilities for critical discourse multiply (Allan, 2016; Leavitt, 2006; Plank, 2011, 2013).

These rewards and complexities characterized the course described in this article. The class, entitled "The Making of a School," joined together the professors and their students with experts in Kenya to create the blueprints for a new girls' boarding school to be built outside the capital in Nairobi. The process of collaboration that we experienced in this class brought into bold relief the

...the collaborative sharing of knowledge and expertise can be rewarding in unprecedented ways, as the walls defining knowledge grow porous, and the possibilities for critical discourse multiply.

InSight: A Journal of Scholarly Teaching 
value of co-teaching and also underscored for us the ways in which emerging technologies and other new forms of pedagogy can enrich student learning. The course engaged with collaborative work on many levels: first, in its being taught by two faculty with complementary areas of expertise, one American and one born and educated in Kenya; second, in that the students worked in collaborative groups around specific areas of school design; and third, in that both faculty and students together consulted with experts "on the ground" in Kenya to formulate all aspects of the school, from mission to budget, curriculum, and site planning. Both the professors and their students came out of this experience with concrete skills for moving forward with the creation of this school, but we also gained a deeper and more nuanced understanding of design thinking, cross-cultural collaboration and the politics of school making. In short, this exercise in school making emerged for us as an object lesson in collaborative work, an experience in which all parties learned a great deal not only about the content at hand, but about new pedagogies, interpersonal relationships, and, perhaps most pointedly, about ourselves.

\section{The Nexus of Collaborative Pedagogy and Design Thinking}

Brufee (1999) writes that literature on knowledge construction, drawn from collaborative interactions, is grounded in three distinct domains. The first focuses on collaboration among members of a single knowledgeable community: peers in the same field. This kind of collaboration occurs when experts read and critique one another's research or co-author scholarship, drawing on like areas of expertise. It is also the domain of the most frequent form of team-teaching. Much of the literature on team-teaching points to its capacity to enliven pedagogy and even spark "joy" (Leavitt, 2006; Rinn \& Weir, 1984). Team-teaching with colleagues in one's department or field can "build deep professional and intellectual bonds" (Jessen-Marshall \& Lescinsky, 2011, p. 34) and can also serve as a model for students for how thoughtful people engage with one another over complex ideas.

The second domain of collaboration occurs when we work at the boundaries between knowledgeable peers (Brufee, 1999), where faculty and students across subjects or fields merge their expertise around a common problem. Recent thinking in the academy, especially in the areas of expanding global understanding, has encouraged these kinds of collaboration as a way to break down the barriers between disciplines and model for students the porous nature of knowledge itself. Arne Koch, dean of Global Engagement at Colby College, for example, describes programming at his institution where faculty in separate divisions travel together to study a common topic or problem, like sustainable farming or barriers to female literacy; afterwards, they develop new courses that attack the issue from diverse perspectives: economic, political, and even literary or artistic (Koch, 2018). Again, this kind of collaboration has its rewards and challenges. Translating ideas across intellectual boundaries requires patience and openness (Plank, 2011).

The third and most challenging form of collaboration occurs between knowledge communities (experts) and outsiders who want to join them. It is a form of sharing that problematizes the very notion of expertise and requires practitioners to rethink traditional models of authority and power. This approach to knowledge 
construction drives the literature on design thinking. Design thinking has been characterized as both a "mindset" and "educational model" (Goldman \& Kabayadondo, 2017; Rauth, Köppen, Jobst, \& Meinel 2010; Renard, 2014). It is a mindset in that it privileges a focus on human values and requires collaborating individuals with varying experiences to value the work of others as crucial to their own success. As an educational model or pedagogy, it requires hands-on work-the conceptualizing and creation of "prototypes" or physical artifacts that are transformed and improved through continuous feedback and testing (Goldman \& Kabayadondo, 2017; Miller, 2015; Sweet, Blythe, \& Carpenter, 2017). As Renard (2014) notes, the design thinking approach can increase students' capacity to recognize opportunities, engage in divergent thinking, and revisit and revise ideas through iteration (p. 414). With roots in the ideas of knowledge construction put forward by educators such as John Dewey and Donald Schön, this approach is increasingly becoming popular in liberal arts college classrooms in the United States (Goldman \& Kabayadondo, 2017; Renard, 2014). Its popularity seems to increase as higher education institutions recognize its potential for addressing the goal of deepening students' critical understandings of and engagement with the "real world" towards positive social change (Miller, 2015, Sweet et al., 2017). Design thinking has emerged as a valuable tool for students to produce works in a real-world context while at the same time allowing for the evaluation of those works to build knowledge in an iterative way (Renard, 2014).

Design thinking serves to challenge the traditional "banking" models of knowledge transmission (Freire, 2015) by positioning students as active constructors of knowledge, helping them reconceptualize the teacher-learner relationship. In adopting the principles of design thinking, faculty must be willing to negotiate the traditional power and authority they typically have over curriculum, teaching, and learning and instead serve as facilitators of learning, as coaches. They must seek to expose students to the cross-disciplinary knowledge and skill sets they need to undertake their team projects. Above all, they must embrace uncertainty engendered by their role. As Johnson (2017) notes, “Those who facilitate design learning must steadfastly negotiate their own fears as they lead others into disequilibrium, uncertainty and radical reframing that reliably occur when designing" (p. 129). As we note in a later section, this negotiation can open up important learning opportunities for students and facilitate a paradigm shift in instructors' views about collaborative pedagogy. Finally, design thinking encourages learners to seek input from outside experts and practitioners in the field. As knowledge becomes democratized through the design thinking process, sources of information, feedback, critique, and support grow wider, as experts and outsiders (Brufee, 1999) work together, pooling experience.

\section{The Making of a School: A Collaborative Course Model}

All these forms of collaboration were mobilized in ED222, "The Making of a School," a course whose explicit mission was to consider the ways alternative forms of education can address fundamental social problems within cultures. The goal of our work together was a concrete one: to design a prototype for an actual girls' boarding school in Kenya, to be built within the next few years, fulfilling the long-time dream of 
one of the faculty teaching the class. That goal required students to address a series of complex questions. Since, in Kenya, quality girls' education remains a challenge (Chege \& Sifuna, 2006; Mugo, Nderitu, \& Ruto, 2016; Mule, 2008; Oruko et al., 2015), how could an alternative model for girls' education resolve some of the cultural and structural forces that thwart girls' success? How can past efforts to address educational injustice inform the present and transfer from one context to another? How might we reconcile a hands-on project like this, given the vast distances and cultural differences that separated designers and users of the school?

The course began with the familiar: a series of readings that outlined historical models for alternative schools created to address perceived inequities. The class looked at early 20th-century U.S. settlement schools for immigrants and at "liberationist" schools founded in American urban centers in the 1960s. Finally, we turned to the highly contested rise of charter schools as sites for educating disenfranchised groups. At this point, we visited a local suburban Chinese immersion charter school in the community and invited the principal of a local Latinx-majority urban charter school, inspired by the principles of Paulo Freire, to speak to the class. With this background, both theoretical and practical, the class then turned to Kenya and the arguments for creating alternative schools in that country. Readings and presentations on Kenya were carefully selected with a mix of history, educational policy and reform, challenges of girls' education, and models of alternative schools. This background laid the groundwork for the final, active work of the term: prototyping the school.

The class of 22 students was then broken into teams of students, each team charged with addressing a different aspect of the school-making process. Based on the readings and visits we had undertaken, students and faculty isolated six areas of focus for the project: school mission and web presence, budget and fundraising, curriculum, building plan, governance and personnel, and student life. The teams met regularly both in and out of class, and we, the instructors, moved from group to group, providing readings, facilitating discussions with Kenyan contacts, and generally collaborating on the groups' emerging plans. At the end of the term, students presented their plans to a public audience through the college's Global Studies Center.

\section{Faculty-to-Faculty}

\section{Forms of Collaboration}

As a co-created and co-taught course, our collaboration began with the preliminary design of the class. That design was necessarily grounded in our own areas of expertise. One of us was a historian of education with a background in curriculum and school reform; the other was an expert on social justice and comparative education, with a particular focus on Africa and the African diaspora. Both of us felt strongly that contemporary policies, whether local or global, needed to be grounded in an understanding of the past and an empathic connection to the present.

All readings were compiled collaboratively and posted on an online shared team drive accessible to all. Student work was evaluated collaboratively, and the scope and content of each individual class was discussed and negotiated in advance of the 
session. As co-teachers, we also participated in monthly "teaching circle" discussions with other faculty members in the college who were using the design thinking approach in their courses. These sessions allowed us to problem-solve alongside faculty who were also grappling with course designs. Staff at the Design Thinking Center provided concrete tools for collaborative brainstorming (markers and multicolored post-it notes; flipchart paper and sample readings, as well as a guest lecture, early-on in the course, to explain the principles of Design Thinking to the students). Professors in math and architecture made themselves available for consultation, as did the GIS Mapping staff, whose contributions to the course will be discussed below.

\section{Faculty-Student Collaboration}

Before students could begin their individual team work, certain shared understandings about the proposed school needed to be negotiated across faculty and students. Though certain "givens" existed a priori (the actual site of the school; the fact of the Kenyan national curriculum), all other decisions were negotiable. Together, faculty and students decided that the school would be themed, that the theme would be "leadership," and that the school would be an all-girls school and a boarding school. The group collaborated, too, in naming the school, voting for a tentative name from among a range of group-generated possibilities. Faculty and students also negotiated the team evaluation rubric for the project portion of the course. Students suggested, and faculty agreed, that they add to the faculty-made team drive both a master document developed by each team (that was regularly updated and shared with other teams) and a spreadsheet developed by one student in which teams reported their weekly progress and posted questions for other teams. Finally, faculty continued to move from group to group until the end of the term, checking in, critiquing, offering new readings or recommendations, and serving, generally, as cheerleaders as the emerging deliverables came into focus.

Faculty collaboration served to change the nature of the faculty-student exchanges. Students witnessed, in almost every class, the dynamics of faculty-tofaculty negotiation, as we debated ideas between ourselves in front of the classroom, disagreed about interpretations of readings, and found common ground through these debates. Modelling this kind of intellectual negotiation seemed to break down barriers between faculty and students, who became increasingly open with us throughout the semester, critiquing readings and suggesting alternative formats for class activities and assignments.

\section{Student-to-Student Collaboration}

Student teams were each composed of three or four students who together needed to negotiate not only what their final deliverables should be composed of but also what form those materials should take. For example, the group assigned to research the physical site of the school presented aerial maps of the area, graphs documenting soil composition, sites for septic and well construction, and rough architectural plans for the school itself. Students charged with budget construction presented an outline of budget categories, examples of budgets from comparable 
schools in the area, and a list of potential funding and grant sources. Students were encouraged to utilize the design thinking process as a way to gain consensus on ideas and work through conflict.

Several teams worked in other areas of the college. The site team worked collaboratively with the school's GIS staff in the Mapping Lab; the curriculum and mission groups worked in the college's Knowledge Lab-an open space with white boards, beanbag chairs, and other materials that encouraged hands-on, iterative work. Teams consulted with other teams as needed, and groups reassembled at the end of each class to share their thinking and ask questions. Design thinking collaboration among students necessitated that each group revisit individual assumptions, consult resources, and rethink their conclusions in an ongoing and iterative way.

\section{Collaboration with Experts on the Ground}

The fourth level of collaboration in the course was the work done with experts on the ground in Kenya or with Kenyan visitors to the college. In the pre-planning stage, one of the instructors spent a summer in Kenya visiting with school founders and touring alternative schools. Some of the contacts established during the visit would later speak with our students via Zoom (a video conferencing tool). Zoomed sessions, in which the entire class participated with Kenyan experts, deepened the collaboration across geographical borders. The collaboration with experts, whether online or in-person, addressed a range of topics. A director of students from an independent school outside Nairobi spoke about student life, parental involvement, and the centrality of wellness programs for students in Kenyan boarding schools. A visiting senator from Kenya, who served on the board of a boarding secondary school, spoke to students about school board composition, funding, and marketing. A visiting Kenyan journalist talked about her personal struggle to access quality education growing up. She also spoke about the development of "soft skills" and the critical importance of out-of-classroom work, clubs, and sports teams for Kenyan girls. Two Kenyans living locally in Massachusetts spoke about ways of funding schools and explained the key role of the African diaspora in supporting educational efforts back home. Students also heard via Zoom from a former curriculum developer at a new and innovative university in Mauritius about the need and strategies for decolonizing the curriculum in African schools, and a Smith student who had interned in the school also shared her experiences with curriculum reform. In all, seven individuals familiar with the Kenyan education context served to encourage and support the work of the students, a crucial piece of the collaborative puzzle and one that helped to offset the students' sense of themselves as privileged outsiders, unequipped to make recommendations across cultures and continents.

In short, all these varied forms of collaboration served to create a complex, innovative, and challenging experience for both faculty and students. Stepping back from the class at the end of the term, we have sought to clarify the experience practically, philosophically, and ethically. The following section enumerates those understandings that have emerged from the class itself and from our ongoing analysis of our work. 


\section{Rewards and Difficulties of Collaborative Pedagogy from the Students' Perspective}

What was the impact of this multi-tiered collaboration on student attitudes and student learning? In their final assessments of the course, students identified collaboration as a major skill gained during the semester. When asked to respond anonymously to the question, "What would you say are the top two or three things you personally gained from this course?" 9 of the 16 students who responded identified collaboration with others. It was frequently mentioned second only to content (knowledge about alternative schools and their contexts), which was mentioned by 10 students. Other gains identified included a new appreciation for the design thinking process (mentioned by 4 students) and effective communication (mentioned by 4 students). We also asked students to let us know what worked or did not work for them with regard to the collaborative teaching/learning model we had adopted for the course. Half of the class responded to this question and conveyed their appreciation of the approach, ranging from collaboration modeled by the instructors to teamwork. One student noted, "Love-team teaching as a soon-to-be teacher myself, and really think partnership we saw in class echoes the true nature of education."

However, there was criticism as well. Many students said they wished they had more time for cross-team collaboration and discussion, a feeling captured by one student who noted, "I loved this model for learning! Everything worked for me except I would have appreciated a different structure to allow for more/deeper check ins with various teams..." The need for more cross-team discussions increased especially toward the end of the semester as the teams prepared for the public presentation of their work. Clearly, the four weeks dedicated to the team project was not enough. Nor was the online team drive used as effectively as we had anticipated, and most students said they simply needed more time to work as a full class, reporting back on the progress they were making in their smaller, interest-based subgroups.

To gauge the students' attitudes about the use of the design thinking process for this course, we asked them, "How useful was the design thinking approach to your team? Would you recommend the same amount, or more or less instruction in this kind of group work strategy?" All the 15 students who responded anonymously to this question found the strategy to be useful-some more than others. One enthusiastic student noted, "A great way of teaching!" Most, however, sought more explicit instruction about the strategy, as well as a more seamless integration throughout the course. Three of the six teams reported that they extensively used the process in their team project.

Although we did not explicitly ask students about their views regarding collaboration with Kenyan partners, their unsolicited comments throughout the semester consistently conveyed the value they derived from this aspect of the course. Evidence of collaboration and iterative thinking was evident as students worked toward team deliverables. For example, the team in charge of developing budget and funding plans conveyed in their team report the importance of multiple layers of collaboration in their team:

Like most other findings in this report, the process of forming the budget was influenced by design thinking. Throughout the semester, the Budget and Funding group reached out to other groups in order to empathize with and 
define their funding needs. We used that information to ideate, prototype, and test different models of presenting these needs in light of no definite costs being available. As our team and others realized new potential costs, our team cycled through those steps until we arrived at [the final] list...Nonclassmates were also essential to our process and will be much more important in the future as plans for the school continue to grow. We had the opportunity to talk with [Kenyan collaborators] and meet with a few potential [Kenyan diaspora] donors. In producing this report, we strived to keep in mind the knowledge, concerns, and advice offered by our outside resources.

For this team, it was clear to us that there was a marked shift from their original North-to-South ideas about funding development to a realization that a funding plan that included Kenyan donors is feasible and ultimately more sustainable. What was instructional for us as instructors is that the varied levels of collaboration in the course allowed for this kind of organic learning.

While we were glad that students did not exhibit the aversion to group work often cited in literature (Allan, 2016), important questions emerged that will guide our future project-based courses. How early in the semester should the team projects begin? What constitutes "sufficient" levels of cross-team collaboration in a project like this? What collaboration tools would be appropriate for maximizing cross-team communication for a project like this? What level of depth on design thinkingtheories, method, philosophies - should students be taught prior to engaging in their team projects? How can collaboration with global partners be deepened in every step of the projects?

\section{Rewards and Difficulties of Collaborative Pedagogy from the Instructors' Perspective Professional Development}

For the two faculty who engaged in the design and teaching of this course, the rewards were profound. Our weekly planning sessions afforded us time to "teach" the readings to one another, to debate issues that arose in the material, and to parse together the dynamics of the class. Indeed, one could argue that collaborative course design and team teaching are among the most effective forms of professional development, providing as they do an opportunity for metacognition and self-scrutiny.

There were a myriad of instances throughout the term when our co-planning yielded deeper understandings that would never have emerged in casual conversations. For example, a conversation about "what the Kenyan young women needed" in their co-curricular experiences revealed the limitations of western liberal assumptions on the part of the American faculty member, whose skepticism about the value of "class trips to Europe" was rebuked by her Kenyan collaborator. Differences of opinion about standards for grading and attendance made for fascinating discussions about pedagogy and the cultural norms that undergird our teaching. These regular debates were highly instructive, especially since they took place within the safe space of our offices between colleagues whose trust grew deeper over the course of the term.

The college's willingness to support the team-taught class, allowing us to count it as a full course-equivalent for each faculty member, communicated their 
understanding that this kind of collaborative work was not only worthwhile but crucial. If teachers are to implement new technologies and extend their work across fields, they may well need the support that comes from teaching in teams. Experimentation and risk-taking felt so much easier with a friendly partner.

\section{Time and Logistics}

Despite these positive outcomes for our professional development, multilevel collaboration of the kind we describe here also necessarily carries with it certain stubborn challenges and hurdles (Benjamin, 2000; Hinton \& Downing, 1998; Letterman -\& Dugan, 2004; Plank, 2011; 2013). The first and most obvious are the logistical ones. Planning a course like ours required a formidable time commitment. Before the course even began, we, the teachers, needed long stretches of time together for planning, communicating with Kenyan advisors, setting up schedules for school visits, and Zoomed interviews with experts. Given our own deep commitment to the projectthe making of a real school-this commitment felt less burdensome than it would be if the course was simply an abstract exercise. Still, institutions that seek to support this kind of hands-on, collaborative, and interdisciplinary work should recognize (and compensate) the exceptional time commitment required for such work.

Another logistical complexity was balancing the various factors involved in supporting the student teams. Student teams worked at different campus sites (the locations team worked in the GIS Center; the budget team worked in the Knowledge Lab; etc.), and faculty moved from place to place, consulting and supporting student work, movement that was cumbersome and created an occasional sense of dislocation and could potentially lead to contradictory advice. Technology, too, created logistical challenges; time differences made working with Kenyan colleagues unwieldy, and technology was sometimes unpredictable, as internet connections were imperfect or failed altogether.

\section{The Problem of "Privilege"}

One unpredicted challenge we faced emerged less from the practical aspects of collaboration than it did from the more abstract and ethical issues associated with this kind of collaborative school making. Almost from the start of the class, some students voiced their concerns about their own ethical stance with regard to the project. How, they questioned, could privileged first-world women make recommendations for best practice for teachers and students they had never met in a country in which they had never lived? That sense of privilege, and the uneasy paralysis that emerges from it in the face of doing good, became a recurring theme in our work. Indeed, though students moved forward with their team deliverables, their unease with the process of that work increasingly emerged. Despite our preliminary efforts to situate our school-building project in the context of historical understandings about other liberationist work, and despite our work to integrate the expertise of Kenyan nationals (including one of the two faculty teaching the class), students expressed repeatedly their sense of themselves as western interlopers imposing their dominance and their privilege on a community they would never know profoundly. Collaborative 
conversations about these concerns became increasingly commonplace as the work advanced and sparked for the two faculty collaborators a rethinking of the meaning of these student-initiated discussions. Clearly, the conversations were important and useful on a number of levels, serving, ironically, to reinforce the very strategy of design thinking that drove the entire exercise. The way in which these complaints were voiced and analyzed, with increasing candor and eloquence, also seemed a natural outgrowth of the collaborative nature of the course.

Whenever this unease was shared with the Kenyan collaborators, students' perspectives shifted somewhat. In two instances, for example, students shared their "interloper" fears and in each case received affirming responses from the Kenyan partners. The Kenyan journalist assured students that Kenyans are global-minded and used to partnering with other countries toward sustainable development. Another consultant, the Kenyan senator, expressed his regret that the proposed school would not be built in his county. Collaboration at the highest level, we reasoned, is always iterative (Letterman \& Dugan, 2004), and the recurring desire to parse the nature of our collaboration (the values that informed it; the authority of the players in the process) was as deeply educative as the school product that was created by the group. Indeed, discussions about privilege, authority, and power-discussions that often take place at Smith College-gained new urgency and complexity as a result of their context here. What does it mean to make something like a school for someone who one knows only through second-hand readings and accounts? What constitutes "sufficient" levels of collaboration to legitimize a project like this? What right do privileged white students have in making recommendations of best practice to disadvantaged or disenfranchised groups? The discussions we had about these issues were surprisingly complex. The final written assessment of one student summarizes well the nuanced understandings produced by this collaborative discourse:

The most important thing I learned about myself in this project was simply how much more I have to learn. This class took everything that I knew or understood about privilege and turned it all upside down...I went into this class with the idea that establishing schools and teaching in developing countries was how I wanted to spend my life, and I couldn't see anything other than the positives of that. I had all of these preconceived ideas about the benefits of education as a driver for social change, and while I still believe in those ideas for the most part, this class really made me rethink the limitations of my own privilege.

In a school where political discussions tend to highlight a single point of view-often the most politically correct and progressive-students here worked their way through a range of viewpoints, made more candid and comfortable because of the collaborative work that preceded those discussions. This was true not only between students, but between students and ourselves.

Perhaps the most rewarding aspect of collaborative pedagogy enacted in this course was that it enabled us to teach the design thinking technique to students who might never otherwise have had the opportunity to engage with this kind of alternative form of learning. In addition to the students' perceptions about the approach discussed above, we observed throughout the semester how the language of design thinking became commonplace in class discussions and in their various written assignments, 
including the process paper each group submitted at the end of the semester. The deliverables they submitted were faithful to the process of creating "artifacts" or "prototypes" that were improved through consultation and feedback. At the final public presentation of their work, students' ease with the language and process of design thinking was evident throughout. Students spoke explicitly about their processes for negotiating controversy and their newfound understanding of how complex tasks can be simplified and clarified when divided among team partners who are equally invested in the outcomes of those tasks. These seemed to us like important life lessons that can be carried into other classes and ultimately into the workplace.

\section{Conclusion}

The semester was a first for us in two important ways. We were finally able to co-teach a course after many years of wanting to do so, and we used the design thinking approach for the first time to organize our course. Design thinking energized us and afforded us the rare opportunity to collaboratively reflect in and on our practice. We became comfortable opening up to each other and to our students about our passion for and vulnerabilities with regard to course content. Despite its less than flawless application in our course, the pedagogy provided our students with rich opportunities, not only to engage deeply with content around the policy, politics, and practice of school making at home and abroad, but also to do this in collaboration with others. It offered us (the course instructors) an opportunity to transform a shared interest in comparative education into a complex and multilayered course that would leverage human and material resources across the campus, in the local community, and beyond our national borders.

If we get an opportunity to teach this course again in the future, we would continue to model collaboration as co-teachers. As noted earlier, many students acknowledged and appreciated this modeling. We would create more opportunities for large-group conversations - perhaps "flipping" the classroom as a way to better facilitate these conversations (EDUCAUSE Learning Initiative, 2012). We found that once students realized we were transparent about our passion, fears, and uncertainties with the project, they mirrored the same transparency and engaged in deep conversations about content, process, and skills. Finally, a study abroad component may be a useful addition to a future iteration of the course. Short-term faculty-led study abroad opportunities, linked to specific courses, have become a popular option for students and faculty at Smith College. Even brief engagement "on the ground," might allow students to begin to negotiate the North-South power dynamics that confounded them throughout the term. Face-to-face meetings with experts onsite would certainly deepen the various forms of collaboration that served as the basis for this challenging and satisfying class.

InSight: A Journal of Scholarly Teaching 


\section{References}

Allan, E. G. (2016). "I hate group work!": Addressing students' concerns about small-group learning. InSight: A Journal of Scholarly Teaching, 11, 81-89.

Benjamin, J. (2000). The scholarship of teaching in teams: What does it look like in practice? Higher Education Research and Development 19(2), 191-204.

Brufee, K. (1999). Collaborative learning: Higher education, interdependence, and the authority of knowledge. Baltimore, MD, and London, UK: Johns Hopkins University Press.

Chege, F. N., \& Sifuna, D. N. (2006). Girls' and women's education in Kenya: Gender perspectives and trends. Unesco.

Dewey, J. (1997). Experience and education. New York: Free Press.

EDUCAUSE Learning Initiative. (2012).

7 things you should know about flipped classrooms. Retrieved from

https://library.educause.edu/resources/ 2012/2/7-things-you-should-knowabout-flipped-classrooms

Freire, P. (2015). Pedagogy of the oppressed. New York: Bloomsbury.

Hinton, S., \& Downing, J. E. (1998). Team teaching a college core foundations course: Instructors' and students' assessments. Richmond, KY: Eastern Kentucky University. ERIC document no. ED 429469.
Johnson, Z. (2017). Teachers as designers of context-adaptive learning experience. In S. Goldman \& Z. Kabayadondo (Eds.), Taking design thinking to school (pp. 126142). New York: Routledge.

Koch, A. (2018). Integrating off-campus study: Colby College's faculty mentoring program. Paper delivered at the Globalizing the Liberal Arts Conference, Soka University, CA.

Leavitt, M. C. (2006). Team teaching: Benefits and challenges. Speaking of Teaching: Newsletter of the Stanford University Center for Teaching and Learning, 16(1), 1-4.

Letterman, M. R., \& Dugan, K. B. (2004). Team-teaching a cross-disciplinary honors course: Preparation and development. College Teaching, 52(2), 7679 .

Miller, P. N. (2015). Is "design thinking" the new liberal arts? The Chronicle Review, B6-B9. Retrieved from https://www.chronicle.com/article/IsDesign-Thinking-the-New/228779

Mugo, J. K., Nderitu, J. K., \& Ruto, S. J. (2015). The 2015 promise of education for all in Kenya: Missed target or new start? ZEP: Zeitschrift für Internationale Bildungsforschung und Entwicklungspädagogik, 38(2), 16-21. 
Mule, L. (2008). Feast or famine for female education in Kenya? A structural approach to gender equity. In M. Maslak (Ed.), The agency and structure of women's education (pp. 67-84). Albany, NY: State University of New York Press.

Oruko, K., Nyothach, E., ZielinskiGutierrez, E., Mason, L., Alexander, K., Vulule, J., ... \& Phillips-Howard, P. A. (2015). "He is the one who is providing you with everything so whatever he says is what you do": A qualitative study on factors affecting secondary schoolgirls' dropout in rural Western Kenya. PloS One, 10(12), e0144321.

Plank, K. M. (2011). Team teaching: Across the disciplines, across the academy. New pedagogies and practices for teaching in higher education series. Sterling, VA: Stylus.

Plank, K. M. (2013). Team teaching. IDEA Paper No. 55, 55.
Rauth, I., Köppen, E., Jobst, B., \& Meinel, C. (2010). Design thinking: An educational model towards creative confidence. In DS 66-2: Proceedings of the 1st International Conference on Design Creativity (ICDC 2010).

Renard, H. (2014). Cultivating design thinking in students through material inquiry. International Journal of Teaching and Learning in Higher Education, 26(3), 414-424.

Rinn, F. J., \& Weir, S. B. (1984). Former champ makes comeback: Yea team. Improving College and University Teaching, 32(1), 5-10.

Sweet, C., Blythe, H., \& Carpenter, R. (2017). Why design thinking should matter to higher education, Part I. The National Teaching \& Learning Forum, 26(3), 5-7.

Rosetta Marantz Cohen is Myra M. Sampson Professor of Education and Child Study at Smith College, where she also serves as Elizabeth Mugar Eveillard 1969 Faculty Director of the College's Lewis Global Studies Center. She teaches courses on the history and philosophy of education, and on women's education, worldwide. Her most recent book is The Work and Lives of Teachers: A Global Perspective (Cambridge University Press, 2017).

Lucy W. Mule is associate professor in the department of Education and Child Study at Smith College in Northampton, Massachusetts. Mule's research interests include curriculum development, service learning, multicultural education, pre-service teacher education, study abroad, and comparative education. She teaches courses in the sociological and cultural foundations of education and has taught gateway and capstone courses for the community engagement and social change concentration at Smith College. 


\section{Appendix}

The following questions informed the observations made in this article regarding student experiences of and learning in the course. We designed the first two questions in response to an invitation that went to all faculty in the College, asking them to submit optional custom questions for the usual end-of-semester course feedback questionnaire. We sent the two questions as we wanted to gather student views on our use of collaboration and design thinking approaches in our course:

1. This is the first time we have taught a course built so wholly around a collaborative project. Can you comment on what worked and did not work for you with regards to this collaborative teaching/learning model?

2. How useful was the Design Thinking approach to your team? Would you recommend the same amount, more or less instruction in this kind group work strategy?

Student responses to the following three questions contained in the College's feedback questionnaire that relate to learning strategies provided us with quantitative and qualitative data that confirmed our observations about the usefulness on collaboration and hand-on learning activities used in the course:

3. Please indicate how helpful [our] teaching methods were in furthering your own learning in this course:

a) Facilitation of activities and discussions, and b) responsiveness to questions.

4. Please indicate how helpful the following structural aspects of the course were in furthering your learning:

a) In-class activities and discussions, and b) out-of-class activities

5. What general learning strategies or study methods did you find most useful in this course?

a) Engaging actively in class discussions and activities

b) Doing class assignments (reading, etc.)

c) Other

The following two questions contained in the College's feedback questionnaire provided us with quantitative and qualitative data that confirmed our observations about student learning in the course:

6. What would you say are the top two or three things (ideas, skills, perspectives, etc.) you personally gained from this course?

7. Please indicate how helpful the following structural aspects of the course were in furthering your learning:

a) The instructor created an effective learning environment.

b) The course contributed significantly to my education. 